\title{
A regional comparison of dietary intakes of 7-year-old children enrolled in observational birth cohort studies on the Isle of Man and in south-west England
}

\author{
P.M. Emmett, E. Tweney, J. Golding and C.M. Taylor \\ Centre for Child and Adolescent Health, School of Social and Community Medicine, University of Bristol, \\ Bristol BS8 2BN
}

There is concern regarding the low amount of fruit and vegetables consumed and high sugar intakes in children's diets. Regional dietary differences in the British Isles could underlie variation in health outcomes, but little is known about these differences. The diets of children across the UK have been described by several studies including the National Diet and Nutrition Survey (NDNS) ${ }^{(1)}$, and in Ireland by the National Children's Food Survey ${ }^{(2)}$. There are very few data, however, on regional differences in overall diets and food consumption in the British Isles. In a closely defined area, the south-west of England, data on the dietary intakes of children have been published and can be used for in depth regional comparisons ${ }^{(3)}$. Our aim was to compare diets of children enrolled in two similar observational birth cohort studies: one in the Isle of Man (IoM-ELSPAC) and one in south-west England (Avon Longitudinal Study of Parents and Children, ALSPAC).

Dietary intakes were assessed by 3-day food records in 1998-2000 in IoM ( $\mathrm{n}=490)$ and ALSPAC $(n=7087)$ at age 7 years. Mean daily nutrient, food and food group intakes were calculated by the same method. Comparisons were made between the studies and with UK national dietary guidelines.

Diets in both regions were adequate for most nutrients except dietary fibre ${ }^{(4)}$. There were differences between the two regions, particularly higher energy, protein and carbohydrate intakes in IoM. IoM children consumed greater amounts of red meat, bread (approximately $+20 \mathrm{~g} /$ day), full-fat milk (approximately $+100 \mathrm{~g} /$ day) and sugar-sweetened drinks (approximately double) (all p $\leqslant$ 0.001). In both groups intake of free sugars was more than three times higher than the UK recommended maximum ${ }^{(4)}$. There were no differences in fruit and vegetable intakes, which were below recommended levels ${ }^{(5)}$.

IoM children had higher intakes of energy and some nutrients and food groups than ALSPAC children with similar low intakes of dietary fibre, fruits and vegetables. There is scope for improvement in children's diets in both regions in order to achieve more balanced diets. This is particularly pertinent with the increasing prevalence of childhood obesity and the UK recommendation to lower the intake of free sugars ${ }^{(4)}$.

\begin{tabular}{|c|c|c|c|c|}
\hline & \multicolumn{2}{|c|}{ IoM-ELSPAC } & \multicolumn{2}{|c|}{ ALSPAC } \\
\hline & Boys & Girls & Boys & Girls \\
\hline $\mathrm{n}$ & 244 & 246 & 3593 & 3494 \\
\hline Energy (MJ) & $7.70(7.53,7.88)^{*}$ & $7.26(7.09,7.43) \dagger \dagger \dagger$ & $7.44(7.39,7.48)$ & $6 \cdot 88(6.84,6.92)$ \\
\hline$\%$ from protein & $14 \cdot 0(13 \cdot 7,14 \cdot 3)^{* * *}$ & $13 \cdot 6(13 \cdot 3,13 \cdot 9) \dagger$ & $13 \cdot 3(13 \cdot 2,13 \cdot 4)$ & $13 \cdot 3(13 \cdot 2,13 \cdot 4)$ \\
\hline$\%$ from fat & $33.9(33 \cdot 3,34 \cdot 4)$ & $34 \cdot 3(33 \cdot 8,34 \cdot 9)$ & $35 \cdot 3(35 \cdot 2,35 \cdot 5)^{* * *}$ & $35 \cdot 6(35 \cdot 5,35 \cdot 7) \dagger \dagger \dagger$ \\
\hline$\%$ from carbohydrate & $55 \cdot 0(54 \cdot 3,55 \cdot 6)^{* * *}$ & $54.9(54 \cdot 3,55 \cdot 6) \dagger \dagger \dagger$ & $51 \cdot 4(51 \cdot 3,51 \cdot 6)$ & $51 \cdot 2(51 \cdot 0,51 \cdot 3)$ \\
\hline$\%$ from free sugars & $18 \cdot 2(17 \cdot 4,19 \cdot 0)$ & $19.0(18.4,19.8) \dagger \dagger \dagger$ & $17 \cdot 5(17 \cdot 3,17 \cdot 7)$ & $17.4(17 \cdot 2,17 \cdot 6)$ \\
\hline Protein $(\mathrm{g})$ & $64(62,66)^{* * *}$ & $59(57,58) \dagger \dagger \dagger$ & $58(57,58)$ & $53(53,54)$ \\
\hline Carbohydrate (g) & $253(246,259)^{* * *}$ & $238(232,244) \dagger+\dagger$ & $239(237,240)$ & $220(218,221)$ \\
\hline Free sugars $(\mathrm{g})$ & $84(80,88)$ & $83(79,87) \dagger \dagger \dagger$ & $82(81,83)$ & $75(74,76)$ \\
\hline Dietary fibre (g NSP) & $11 \cdot 1(10 \cdot 6,11 \cdot 5)$ & $10 \cdot 2(9 \cdot 8,10 \cdot 5)$ & $10 \cdot 8(10 \cdot 7,10 \cdot 9)$ & $10 \cdot 0(9 \cdot 9,10 \cdot 1)$ \\
\hline
\end{tabular}

Values are mean $(95 \% \mathrm{CI})$

NSP, non-starch polysaccharide.

Statistically significant difference by sex between IoM and ALSPAC (ANOVA): boys: ${ }^{*} p \leqslant 0.05,{ }^{* *} p \leqslant 0.01,{ }^{\star \star *} p \leqslant 0.001 ;$ girls: $\dagger p \leqslant 0.05 ; \dagger \dagger p \leqslant 0.01 ; \dagger \dagger \dagger p \leqslant 0.001$

1. Gregory J, Lowe S (2000) National Diet and Nutrition Survey: young people aged 4 to 18 years. Volume 1: Report of the diet and nutrition survey. London.

2. Irish Universities Nutrition Alliance (2016) National Children's Food Survey. http://www.iuna.net/?p=27 (accessed 1 September 2016)

3. Glynn L, Emmett P, Rogers I (2005) J Hum Nutr Diet 18, 7-19.

4. Scientific Advisory Committee on Nutrition (2015) Carbohydrates and health. Norwich: TSO.

5. NHS Choices (2017) http://www.nhs.uk/Livewell/5ADAY/Pages/5ADAYhome.aspx (accessed 8 March 2017). 